\title{
How should strategy prevail if organisations are seen as having the properties of complex adaptive systems?
}

\author{
Sthandiwe Mthuli \\ KwaZulu Natal Legislature \\ KwaZulu Natal Provincial Government, South Africa \\ Shamim Bodhanya \\ Nafiisa Sobratee \\ University of KwaZulu Natal, Durban, South Africa
}

\section{Keywords}

Strategy-making, organisational success, emergent behaviour, Complex Adaptive Systems, leadership

\begin{abstract}
Conventional organisations are continuously and increasingly becoming more complex and turbulent and there is a need for an alternative conception of strategy-making to assist them. Several strategy formulation approaches have surfaced over the years and a few have been utilised. Conventional strategy-making has been assumed to be a decision process involving a Chief Executive Officer (CEO) followed by subsequent implementation. Research in strategy started with an interest in a single actor focusing on the characteristics and choices of top management disregarding the messiness of the process. Starting from the 1970's, we review systematic studies that contrast the perspectives approach to strategy where the metaphor of a "messier emergent process" is preferred. Thus, Mintzberg (1978), Grant (2003), Mason (2007) and Bodhanya (2011) view strategy-making within organisations as operating within the context of dynamical systems. We argue that for organisations to achieve organisational success in today's turbulent and complex environment, a different approach, dissimilar to traditional conventional organisations which has proved to be incapable and unsuitable of in designing strategies that are able to address complex problems in real world situations, is required. At the same time, for strategies to enjoy the full support of middle managers and employees, remain competitive, relevant and successful in implementation in their local complex, turbulent environment, there is a dire need to adopt different ways of formulating strategy in their organisations.

This paper proposes a different theoretical perspective of managing complex, turbulent environment organisation through the Complex Adaptive Systems (CAS) approach.
\end{abstract}

\section{Acknowledgement}

The authors would like to thank the University of KwaZulu Natal for funding this publication.

Corresponding author: Nafiisa Sobratee Sthandiwe Mthuli

Email address for corresponding author: nsobratee@yahoo.com MTHULIS@kznleg.gov.za

First submission received: 4th February 2017

Revised submission received: 12th March 2017

Accepted: 5th April 2017

\section{Introduction}

Numerous authors define strategy in various ways, influenced by different schools of thoughts, philosophies and backgrounds. Literature indicates that strategy is a dynamic process that can best be realised by learning the actions of employees within an organisation and, in particular, 
the activities of strategy actors at the functional level. (Chackavarthy and Lorange, 2003). In today's world, organisations have become increasingly complex and operate in turbulent environments. Complexity occuris as a result of inter-relationships, interactions, and inter-connectivity of elements within and between a particular system and its environment. Richardson (2008) argues that complexity thinking is a specific attitude towards one's ideas about the world and a perspective that is more sensitive to intricacies that are inherent in one's daily experiences. It is therefore associated with the linking of agents within and between a schemata/ system and its environment. Many systems are characterised by complex behaviours resulting from the links which in turn emerges as a result of non-linear, complex, turbulent nature of the environment. These systems have come to be known as Complex Adaptive Systems.

In this paper, we give a theoretical background on the contrasting perspectives to strategy namely: (i) organisations' conventional perspectives and (ii) approaches to strategy-making and organisations as Complex Adaptive Systems approach (CAS). The specific objectives are to present the fundamental perspective of Complex Adaptive Systems; apply a complexity perspective to organisations and strategy-making process and to discuss important debates regarding strategymaking in complex adaptive organisations.

\section{Approach}

The main purpose of this paper is to give a thorough literature review on how strategy is made in organisations operating in complex, turbulent environments and how CAS perspective offers a radically different perspective from conventional organisation for effective organisational strategy-making practices. This will be achieved by outlining the importance of strategy in an organisation while drawing on a comparison of the theoretical approaches in complex organisation. The paper is largely based on a substantive interrogation of the literature which will conclude with the authors' preferred theoretical position in relation to strategy-making in organisations operating under multi-dimensional and turbulent environments.

\section{Organisations as Complex Entities}

\subsection{Strategy- Making in a Conventional Organisation}

For the purpose of this paper, the definition of strategy Hitt, Ireland \& Hoskisson et al. (2012) is used which defines it as an integrated and coordinated set of commitments and actions designed to exploit core competencies and gain a competitive advantage. Common to definitions of strategy, is the belief that the end-product is an achievement of a goal or objective within a short or long term. Bodhanya (2011) argues that conventional organisations are based on a one-dimensional perspective of the strategy which is unhelpful and amount to a reductionist approach of producing a variety of wish lists and aspirations based on strategic planning processes. Moreover, he maintains that they are built from faulty foundation assumptions which are unattainable as they are not heterogeneous in nature (Bodhanya, 2011). Other authors that support Bodhanya's arguments are Grant (2003) and Mintzberg (1978) who argue that conventional approach to strategy-making is based on major propositions that they are predictable, controllable, linear, and follows a hierarchical level.

Research in strategy dates back to the early 1960's with major interest in the extraordinary top management focus of choice perspective of strategy- making process. The Harvard Business School model further elaborates on the role of the top management in shaping organisations through strategy goals and objectives which later became widely known as a sequential, rational as well as a customised process. The assumption was that a relatively small group of the upper level authorities possess the power to make strategic decisions, followed by a subsequent implementation by those whose positions are below theirs. Traditional studies to strategy-making are by and large experimental and descriptive without telling us what is happening inside the 'black box' of the organisation, that is, the top management's personalities and biases, and preferences may affect the type of choices and conservations held towards designing an organisational strategy. 
According to the conventional organisation's strategic perspective, top management designs the organisation's strategic and organisational context and, enriches realised strategy with new content and gives a new direction. On the contrary, middle and front line manager's' responsibilities are to develop specific strategic initiatives. However, learning in this instance is not articulated within the whole company as certain activities are executed by certain agents, resulting in the lack of strategy evolution as a result of aggregation of contributions received from various hierarchical levels in an organisation.

As time progressed, these issues became eminent and up to the mid- 80 's, there was then a marginal shift in the strategy content in order to explain strategy as a function of its environment (Porter, 2010). Again, this orientation favoured the hierarchical view of the management deciding on behalf of the organisation based on calculated rationality. RAs research on strategy- making began to flourish into a diversified field, resultinged in a concern to confront the choice model with a more collective social learning perspective of strategy- making. Systematic studies in the 1970's contrasted the choice perspective approach to strategy with a more detailed description of a messier partly emergent process (Bower, 1970; Mintzberg 1978). Based on this viewpoint, strategy-making gradually came to be viewed as a complex social learning process involving multiple levels of stakeholders with diverse but interconnected strategic roles (Floyd and Lane, 2000). The ambiguity between differentiating strategy-making from its implementation characteristic in the choice perspective became increasingly confronted as a false division of work between executives who viewed themselves as 'think engines' of the organisation and the rest of the employees as implementers. As a result of this, there was a shift from a strategy-making process from being perceived as a strategic choice into being perceived as a strategic change, now known as CAS (Metcalf and Benn, 2013, Wollman and Steiner, 2017).

Though strategic choice perspectives assumed that new strategies resulted from the executive's intent, strategic change came to be viewed as stemming from autonomous initiatives elicited by problem-solving experimentation at all levels. As a result, it became less of a process of choice and more of a social learning process that occurs over time as agents with schemata adapt to an evolving environment. Strategy-making, as CAS, gained impetus as a result of the shift. In particular, allowing the Resource Based View into a dynamic, complex capacity theory suggests path-dependence, knowledge creation and learning processes. (Mintzberg 1978; Zhou 2008; Miguel \& Joao 2006; Jarzabkowski. 2004). It is further argued that information resulting from realised strategy stimulates emergent strategies that were not initially intended for in the strategy.

According to CAS perspective of an organisation operating in turbulent environment, emergence occurs as a result of a series of an interactions, strategic conversations, inputs amongst agents which co-evolve as a result of a feedback loop resulting in new objectives and goals for the organisation not originally deliberated (Mirabeau and Maguire, 2014; Martin, 2014). Emergent strategy, according to recent authors of strategy- making are not only realised as learning unfolds but are realised with future intended strategies. In other words, the authors are arguing that there is a high probability that these learning's in organisations may co-exist. In contrast, other authors (Burgelman, 1991; ,Dufva, Könnölä \& Koivistaet al., 2015) are interested in the multi-actor, multilayered feedback nature of strategy- making process as they hint that the strategy-making process captures a self-organising component of the strategy as it looks at interactions and, networks between agents that contribute to the formation of an organisational strategy in numerous ways.

\subsection{Complex Adaptive System (CAS) Perspective of an Organisation: Complex, Turbulent Environment}

An underlying theoretical assumption regarding strategy or strategising is that it is well and alive, when the truth is that formulating a strategy is one of the prominently evolving management tool used in this day and age. Rigby (2005) debate that some theorists have even gone into an extent of writing about strategy as if it is a philosophy that is either 'emergent' or 'deliberate'. 
Organisations operating in complex, turbulent environments captures a notion of complex systems that has a densely populated collections of agents, individuals or organisations that act independently and in relation to others. It differs from other systems in a sense that its interactions with others within and outside the system cannot be separated and understood through its subsystems. However, its interactions with and amongst other agents is non-linear, uneven and most importantly shapeless. Richardson's (2008) emphasis is that causality is only achieved through networking rather than singular interactions which representsis a profound shift that calls into question conventional models and methods of linear causality. Foundational characteristics of Complex Adaptive Systems (CAS) are self-organisation, and emergence. Self-organisation is a process whereby systems agents and networks interact, recombine in generating new forms of behaviour and the property of emergence refers to this rising from within and below of new behaviour in the system caused by the self-organisation as a non-linear feedback which is the most critical dynamics of CAS.

Long standing strategy intellectuals such as Chandler (1973),; Child (1972),; Ansoff (1965),; Andrews (1971) and; Porter (1980), just to mention a few, defined strategy- making process in traditional ways as a decision making process that is rooted in models of individual, executive choices. On the other hand, proponents of strategy-making as dynamical systems such as Mintzberg (1978), Bower (1970), Schilit (1987) and Kanter (1981) believed strategy to be a social learning process that is rooted in models of Complex Adaptive Systems. The former school of thought believed that top managers and/or, executives are the only decision makers in relation to strategic vision based on hierarchical power. Contrary to that belief, Mintzberg (1978) and other authors mentioned above opposed the view and argued that decision making cannot be owned by a singular group but is rather a multi-stakeholder effort with the middle management being the mediators based on their transitional positions within the organisation. Furthermore, the conventional thinkers believed that the core processes of strategy-making follows a sequence of executive management's analysis and choices which is followed by the middle management and the rest of the employees implementing the strategy formulated and controlled. This, in other words, informs us that there is a distinction between those that think for the organisations and those that act upon thoughts. Mintzberg et al. (1978) argues against this notion.

The core process of strategy-making entails an evolution of ideas generated from strategic conversations at all levels which are developed, executed, re-integrated as a result of continuous interplay of thinking and acting. In our view, Mintzberg' s argument holds in a sense that through constant re-structuring of ideas and inputs, it results in the development of even newer ideas referred to as "emergent" in CAS approach. If only certain individuals control, predict and decides on the best interest of the entire organisation and its employees, there are less chances of its implementation succeeding. For example, in one of the co-authors"s work environment, the Secretary of the Legislature whose position is equivalent to a CEO in an organisation, the Speaker, and Directors of Units are solely responsible for formulating strategy in the KwaZulu Natal (KZN) Legislature. The Sector Oversight Model (SOM) is but one example of a strategy that was designed by all of these executives at a higher legislative level called the Secretaries Association of the Legislatures of South Africa (SALSA). The SOM was later adopted by all legislatures as 'thee' strategy to go for all legislatures. In as far as implementation of this is concerned, there is only one legislature that has successfully implemented it: Gauteng Province; simply because they are the founders and they designed it with the complex and turbulent environment in mind. Other legislatures assumed the legislature system was linear, predictable and controllable. As a result, KZN Legislature has abandoned this strategy and has begun to employ an alternative type of consultation with the legislature staff which is CAS in nature.

Another example to consider is the case of recruitment of personnel in the public education sector in South Africa. Human Resource managers have to deal with the complex challenge of 
integrating recruitment selection with training and development to fast track service delivery, and aligning recruitment objectives with the broader plans of the government to ensure that when recruitment is done, the process reflects an understanding of the gaps that has to be filled. The challenge comes from mainstreaming a range of different issues including Affirmative Action in terms of gender, redressing the country's apartheid era imbalances, employment of foreign nationals while at the same time ensuring that the recruited personnel are able to deliver in their roles (Parliamentary Monitoring Group, 2006). In this case also, the CAS approach would aid in factoring all the issues relevant in optimising the recruitment process.

Conventional authors of strategy argue that, in term of context, the complexity of the strategy can only be managed by a single actor; executives only (Chandler, 1973; Child, 1972; Ansoff, 1965; Andrews, 1971; Porter, 1980). Authors with a CAS perspective (Mintzberg et al., 1978; Schilit, 1987; Richardson, 2008) disagree on the basis that complexity is beyond just one actor's ability and power to incorporate fragmented pieces of information, knowledge and conversations but requires a collective effort. Another author supporting Richardson's (2008) argument is Zhou (2008) who emphasises that complex systems often exhibit the capacity to self-organise or adapt even without influence. Grant (2003) has a similar view that organisations around the world are facing rapidly changing environment and, in turn, rapid change requires strategies that are flexible and creative.

Conventional organisations are predictable and controllable provided enough information is available and regulatory measures are implemented. This approach is and continues not to be able to deal sufficiently with complex, dynamic nature of organisations. It focuses largely on attempting to understand organisations and quantifying them rather than by adapting to them. An emerging alternative to dealing with complexity in organisations is to acknowledge that they cannot be controlled but rather are adaptable. If that is achieved, it then fulfils the characteristics of complex adaptive systems which is more likely to stimulate further development and performance. These characteristics emerge largely from the interactions and patterns within the system largely known as strategic conversation.

Organisations, as CAS, encourage activities that enables self-organisation and adaptation as they benefit all stakeholders: the top management that is assumed to be making decisions, predicting and controlling the organisation and middle managers who are assumed to carry out implementation of the strategy. The notion of self-organising is related to power distribution in organisations through receiving inputs from all stakeholders affected in the organisation. It is critical to note that there may be resistance to change especially from those that have for over years traditionally made strategic decisions for the organisation, fearing that they may lose power. Giving away power may mean defeat and weakness to them but the value of inputs gathered cannot be compared. As a result, these may be a stumbling block towards change instead of being change agents or champions. While one cannot guarantee that that if a complex, turbulent organisation adopts a CAS perspective, the system will self-organise confidently, however self-organisation that is based upon impartial input and according to good agreed principles and values is likely to yield positive results and achieve best outcomes that enhance the interests of all stakeholders in the organisation.

Zhou (2008) argues that in an ideal situation where good principles and values are in place, stakeholders have adequate information such thatand their power is matched with interest, a good outcome is almost certain. Similarly, Grant (2003) argues that conventional organisations designing strategies that assumes that the future is more likely to be similar to the present situation without taking into account the complexity, turbulence nature of the environment does not hold in the real world. CAS offers an alternative conception of strategy-making and upholds that strategic decisionmaking processes should be unpredictable, uncontrollable, inefficient, proactive, continuous and diverse. If complexity and uncertainty makes decision making difficult, then self-organising becomes more conducive to high performance rather than the top-down hierarchical approach. Strategy- 
making in turbulent, unproductive organisational environment includes scenario planning, strategic intent, vision, strategic innovation, complexity and self-organisation (Grant, 2003). However, scenario planning should merely envisage alternative views of the future and not predict it, while strategy needs to be concerned with instituting clarity of direction within short-term flexible strategic decision. Long term goals could only be articulated through the vision and mission statement of an organisation and committed to through the strategic intent. Traditional organisations fail to distinguish between planning and strategizsing required in new strategies of the new external environment. Mintzberg's (1978) and Pascale's (1999) arguments states that strategy-making in organisations operating in complex, turbulent environment should be organic, unsystematic and an informal process that receives conceptual reinforcement from complexity theory.

\section{Discussion}

Strategy-making in contemporary organisation observes emergent strategy over a period of time. That is, intended strategy (strategic planning and visioning) defines a desirable situation that guides managerial actions. Realised strategy besides being the product of the top-down and bottomup implementation process, defines a specific context in which distinctive learning process takes place. Strategists, at all levels, are required to frequently modify the content and levels of goals captureds in strategic intentions, to include CAS's feedback loop and far-from-equilibrium characteristics, thus consolidating strategic gaps which while on the other hand may not be totally eliminated when intentional strategy is continuously adapted- CAS's feedback loop and far-fromequilibrium characteristics. In other words, the role that time as an artefact plays in a strategy to be realised is crucial. Feedback loop in this instance does not necessarily mean complete change in belief and value, but rather refers to the refining of a realised strategy without change in the fundamental supporting ideas. This again, is critical in an organisation operating in a turbulent environment because it encourages the company to constantly re-examine its goals in the long run and yet, not necessarily meaning the goal could be achieved sooner or later.

It is a well-accepted belief in science that people learn from the results of their past actions. Strategy is not different from this belief as the management is highly likely to repeat actions that yielded positive results and disregard those that did not. What is critical to stress in this regard, is that, in a messy environment, negative feedback is equally important as positive feedback, as the organisation may need to revisit its sequential activities leading to an emergent strategy and learn from it. That says, adaptation is a continuous, ongoing process.

Grant (2003) nonetheless argues that strategy-making processes continue to be more decentralised, less staff-driven, and more informal while strategic plans themselves have become shorter term, more goal- focused, and less specific with regards to actions and resource allocation. Mazzola and Kellermans (2010) offers a critic towards conventional organisation's' perspective of strategy-making and argues that it often cannot explain organisational dynamics. This collectivist view of strategy-making cannot inform what is happening at the micro-level of organisations. Moreover, complex geographically-dispersed organisations could not by far be managed by small teams but require interactive leadership throughout the organisation. The CAS perspective of an organisation is that the middle management has the capacity and strategic influence similar to top management, however, what is critical is understanding interactions among multiple agents of schemata across multiple levels. Strategy implementation in complex and turbulent organisations, if the top management encourages strategic conversations between employees in strategy-making, is likely to yield positive results. However, one cannot ignore the fact that further research is required in providing insight into cognitive, psychological and effective resources that enables middle management to manage their personalities, emotions in the face of top managers (decision-makers).

Recent research output indicate that a paradigm shift has occurred in the field of strategic management such that leadership is now viewed as a property of the collective, not the individual. Cullen-Lester \&and Yammarino (2016) report how new theories such as shared leadership, flock 
leadership and collective leadership have been applied by recent authors. Their work recognisze that teams, organiszations, coalitions, communities, network, systems and other collectives carry out leadership activities and functions through collective social behaviours and processes that are distributed and change over time. Increasingly complex workplaces, business challenges and social problems requires that collective engagement capabilities be developed through both formal and informal relationships (Friedich, Griffith \& Mumford et al., 2016; McHugh et al., 2016)

Moreover, changing trends in technology and customer needs in turbulent and unpredictable environments require firms to become more aware of their adaptability for sustainable competitive advantage, in general, and in the development of successful new products, and leadership styles that boost product innovativeness. Akgun, Keskin, Byrne \& Ilhan et al. (2014) found that mechanisms of CAS partially mediate the relationship between adaptive management practices and firm product innovativeness. Doz and Kosonen (2010) sets out practical, actionable steps that a CEO and a corporate leadership team can take to foster a more purposive - and more strategic - evolution and adaptation of business models. The authors studied successful business transformation in a range of companies which were re-conceiving their models- among others, Nokia, easy Group, HewlettPackard, System Analysis and Programme Development (SAP) and Kone are used as examples. Three core meta-capabilities, namely strategic sensitivity, leadership unity and resource fluidity, wereas seen as essential to maintaining agility within organisations. Of these three, leadership unity is a determinant in enabling the new required adaptive environment that would enable flexible transformation at the micro-level (firm level). In Aa more recent work authoredperformed by Giachetti and Marchi (2016), strategic intensity was found to demarcate firms' performance in becoming market leaders at the macro-level. They explicate how Nokia, the only company to successfully introduce the highest number of innovations related to the digital standard, in the late 1990s and Samsung, the first to quickly increase the number of Android-based smart phones in its portfolio, at the beginning of the 2010s were able to strategise on the 'windows of opportunity' that emerged to exploit the rapidly changing markets.

Another dimension to consider in contemporary strategy-making is the rapid global transformation in the communication landscape. Organisations in the public and private sector need to be mindful of social media-instigated crises which have become more frequent and severe (James, Wooten, \&Dushek, 2011James, Wooten, \& Dushek, 2011). Organiszations struggle to make sense of how to manage and lead in this new ecosystem (Kietzmann, Hermkens, McCarthy, \& Silvestre, 2011; Cheung, 2016). Whereas crisis management activity is largely reactive in nature, crisis leadership purports a more proactive stance and highlights a set of behaviors intended to positively influence multiple stakeholders (James \& Wooten, 2005). The work of Gruber, Smerek, Thomas-Hunt \& James et al. (2015) focus on how the initial sense- making process of managers shapes the ability to respond to crisis events which spread as a result of sharing of messages on the micro-blogging site Twitter. Within the contemporary business environment, virtual platforms have accelerated the speed at which information is shared, have amplified the reach of messages, and solidified the ability of disparate individuals to organisze. In crisis management, in which there is some degree of systems failure, e.g. in emergency situations, leaders need to apply a combination of skills related to emergency management, change management, and transformational leadership. This requires contingent application of emergent abilities whereby different circumstances call for different competencies (Van Wart and Kapucu, 2011). Its study would help to improve the state of normal science of leadership.

\section{Conclusions}

Conventional strategic choices followed by implementation are cumbersome in organisations where change is pervasive, fast, and unpredictable. While important knowledge is developed in conventional strategy-making, we argue that the meta-theoretical paradigm upon which it rests is increasingly awkward and flawed in the face of a radically dynamic organisation. In contrast to 
traditional strategy- making, we emphasisze that complexity theory, as articulated through the properties of complex adaptive systems (CAS) thus far, offers an integrative framework that provides a robust platform for understanding the adaptive responses of organisations in the face of the complex and turbulent environment now common in most organisations. CAS offers organisations an opportunity to develop mechanisms that encourage certain behavioural outcomes which are more likely to yield positive fruits.

\section{References}

Akgün, A. E., Keskin, H., Byrne, J. C., Ilhan, Ö.Ö. (2014). Complex adaptive system mechanisms, adaptive management practices, and firm product innovativeness. RED Management 44: 18-41.

Andrews, K. R. (1971). The Concept of Corporate Strategy. Dow Jones-Irwin, Inc. Homewood, Illinois Ansoff, H. I. (1965). Strategic Management. Corporate Strategy, McGrawHill. New York.

Bodhanya, S. (2011). LED strategy formulation as an evolving process: strategic planning tools arte facts facilitating strategic conversation. Skills at Work: Theory and Practice Journal 4: 9-19.

Boisot, M. and Child, J. (1999). Organizations as adaptive systems in complex environments: The case of China. Organization Science 10(3): 237-252.

Bower, J. L. (1970). Managing the resource allocation process: A study of corporate planning and investment. Harvard University Press, Boston.

Burgelman, R. A. (1991). Intra-organizational ecology of strategy making and organizational adaptation: Theory and field research. Organization Science 2(3): 239-262.

Chakravarthy, B. and Lorange P. (2003). Strategy process: Shaping the contours of the field. WileyBlackwell, Oxford.

Chandler, A. D. (1973). Strategy and Structure: Chapters in the History of the [American] Industrial Enterprise, MIT Press, USA.

Child, J. (1972). Organizational structure, environment and performance: The role of strategic choice. Sociology 6(1): 1-22.

Cheung, M. (2016). Using the Power of Social Consciousness to Influence International Organizations and their Evolving Leadership: The Impact of Social Media on the Public Health Debate. Journal of Health and Biomedical Law 12:169-217.

Cullen-Lester, K.L. and Yammarino, F.J. (2016). Collective and network approaches to leadership: Special issue introduction. The Leadership Quarterly 27: 173-180.

Cunha, M. P. e. and J. V. d. Cunha (2006). Towards a complexity theory of strategy.Management Decision 44(7): 839-850.

Cvelbar, L. K. and L. Dwyer (2013). An importance-performance analysis of sustainability factors for long-term strategy planning in Slovenian hotels, Journal of Sustainable Tourism 21(3): 487-504.

Doz, Y. L. and Kosonen, M. (2010).Embedding Strategic Agility: A Leadership Agenda for Accelerating Business Model Renewal. Long Range Planning 43: 370-382.

Dufva, M., Könnölä, T. and Koivisto, R., 2015. Multi-layered foresight: Lessons from regional foresight in Chile. Futures73: 100-111.

Escobar, A. (2005). Other worlds are (already) possible: cyber-internationalism and post-capitalist cultures. Textos de la Cibersociedad (5): 1.

Floyd, S. W. and Lane, P. J. (2000). Strategizing Throughout the Organization: Managing Role Conflict in Strategic Renewal. Academy of Management Review 25(1): 154-177.

Friedrich, T.L., Griffith, J.A., Mumford, M.D. (2016). Collective leadership behaviors: Evaluating the leader, team network, and problem situation characteristics that influence their use. The Leadership Quarterly 27(2): 312-333.

Friga, P. N. (2009). The McKinsey Engagement. A Powerful Toolkit for More Efficient \& Effective Team Problem Solving. McGraw Hill, New York. 
Giachetti, C. and Marchi, G. (2016). Successive changes in leadership in the worldwide mobile phone industry: The role of windows of opportunity and firms' competitive action. Research Policy 46: 352-364.

Giacomoni, M., Kanta L., Zechman E. M. (2013). Complex Adaptive Systems approach to simulate the sustainability of water resources and urbanization.Journal of Water Resources Planning and Management 139(5): 554-564.

Grant, R. M. (2003). Strategic planning in a turbulent environment: Evidence from the oil majors. Strategic Management Journal 24(6): 491-517.

Grant, R. M. and Jordan J. J. (2015). Foundations of strategy. John Wiley \& Sons.

Gruber, D. A., Smerek , R. E., Thomas-Hunt, M. C., James, E. H. (2015). The real-time power of Twitter: Crisis management and leadership in an age of social media. Business Horizons 58: 163172.

Healey, P. (2009). In Search of the "Strategic in Spatial Strategy Making 1." Planning Theory E Practice 10(4): 439-457.

Hitt, M., Ireland R. D., Hoskisson R. (2012). Strategic management cases: competitiveness and globalization. Cengage Learning, Stanford, USA

Kanter, R. M. (1981). The middle manager as innovator. Harvard Business Review 60(4): 95-105.

James, E.H., Wooten, L.P., Dushek, K. (2011). Crisis management: Informing a new leadership research agenda. The Academy of Management Annals 5 (1): 455-493.

James, E. H., Wooten, L. P., Dushek, K. (2011). Crisis management: Informing a new leadership research agenda. The Academy of Management Annals 5(1): 455-493.

Kietzmann, J. H., Hermkens, K., McCarthy, I. P., Silvestre, B. S. (2011). Social media? Get serious! Understanding the functional building blocks of social media. Business Horizons 54(3): $241-$ 251.

Lane, P. J., Salk, J. E., Lyles, M. A. (2001). Absorptive capacity, learning, and performance in international joint ventures. Strategic Management Journal 22(12): 1139-1161.

Martin, L.R. (2014). The big lie of strategic planning. Harvard Business Review 92: 3-8.

Mason, R. B. (2007). The external environment's effect on management and strategy: a complexity theory approach. Management Decision 45(1): 10-28.

Mazzola, P. and Kellermanns, F. W. (2010). Handbook of Research on Strategy Process. Edward Elgar Publishing, Cheltenham.

McHugh, K.A., Yammarino, F.J., Dionne, S.D., Serban, A., Sayama, H., Chatterjee, S., (2016). Collective decision making, leadership, and collective intelligence: Tests with agent-based simulations and a Field study. The Leadership Quarterly 27(2): 218-241.

Metcalf, L. and Benn, S., (2013). Leadership for sustainability: An evolution of leadership ability. Journal of Business Ethics 112(3): 369-384

Mintzberg, H. (1978). Patterns in strategy formation Management Science 24(9): 934-948.

Mirabeau, L. and Maguire, S., 2014. From autonomous strategic behavior to emergent strategy. Strategic Management Journal 35(8): 1202-1229.

Parliamentary Monitoring Group (2006). Recruitment Strategies for the Public Service: Briefings. Meeting Report. Public Service and Administration, Performance Monitoring and Evaluation Committee. Available at https://pmg.org.za/committee-meeting/7057/. Accessed on 24 February 2017.

Porter, T. (2010). A complexity perspective on strategic process research. The Handbook of Research on Strategy Process. Edward Elgar Publishing, UK, pp. 350-368.

Prewitt, J. E., Weil R., McClure A. Q. (2012). A Complex Adaptive Systems Approach to Strategic Planning.Asian Journal of Business and Management Sciences 1(11): 94-99.

Richardson, K. A. (2008). Managing complex organizations: Complexity thinking and the science and art of management. Emergence: Complexity and Organization 10(2): 13. 
Rigby, D. (2005). Management tools 2005: An executive guide. Available at: http://www.bain.com. Accessed on 14 Nov 2016.

Schilit, W. K. (1987). An examination of the influence of middle-level managers in formulating and implementing strategic decisions. Journal of Management Studies 24(3): 271-293.

Steele, W. (2011). Strategy-making for sustainability: An institutional learning approach to transformative planning practice. Planning Theory E Practice 12(2): 205-221.

Van Wart, M. and Kapucu, N. (2011). Crisis management competencies: The case of emergency managers in the USA. Public Management Review 13(4): 489-511.

Wollmann, D. and Steiner, M.T.A. (2017). The Strategic Decision-Making as a Complex Adaptive System: A Conceptual Scientific Model. Complexityhttps://doi.org/10.1155/2017/7954289

Zhou, P. (2008). An adaptive framework for managing knowledge in e-government. 2008 International Symposium on International Symposium on Knowledge Acquisition and Modeling, Wuhan, China. DOI: 10.1109/KAM.2008.57 